khi sử dụng dịch vụ giảm đau sau mổ tại nhóm bệnh nhân mổ khớp-cột sống là cao (93.04\%). Còn khá nhiều người bệnh chưa có khả năng chi trả chi phí dịch vụ và mong muốn được BHYT hỗ trợ cùng chi trả. Sự nhận thức đầy đủ về dịch vụ giảm đau sau mổ của điêu dưỡng chưa như mong đợi và điều này cân thay đổi để nâng cao hơn nữa chất lượng và hiệu quả điều trị.

\section{TÀI LIÊUU THAM KHẢO}

1. Lê Thị Kim Ngân (2013), Đánh giá mức độ hài lòng của bệnh nhân điều trị nội trú về chất lượng dịch vụ tai bệnh viện ĐKTW Cần Thơ. Tạp chí Kh̉oa học, Đại học Cần Thơ.
2. Gan TJ., (2014), Incidence, patient sastifaction and perceptions of post surgical pain: results from a US national survey. Current Medical Research and Opinion.

3. Vũ Hoàng Anh (2017), Sự hài lòng của người bênh sử dụng dich vụ giảm đau sau mố tai khơa Phâuu thuật cột sống viện CTCH-Bệnh viện Việt Đức năm 2017. Hội nghị khoa học thường niên Viện $\mathrm{CTCH}$ lần thứ V.

4. Nguyến Ngọc Phước (2014), Đánh giá sự hài lòng của người bệnh nội trú và người nhà người bệnh về chất lượng dịch vụ y tế tại Viện Tim Mạch - Bênh viên Bach Mai. Hội tim mach Viềt Nam.

5.Trân Sỹ Thắng (2014), Khảo sát sự hài lòng của bệnh nhân nội trú với sự phục vụ của điều dưỡng tại Bệnh viện ĐK Hà Tĩnh.

\title{
ĐÁNH GIÁ MỨC Độ HÀI LÒNG CỦA NGƯờI BÊ̂NH VÀ CÁC YẾU TỐ ẢNH HƯởNG ĐốI VỚI CẤP PHÁT THUỐC NGOẠI TRÚ DỊCH VỤ TẠI BỆNH VIÊ̂N THỐNG NHẤT
}

\section{TÓM TẮT}

Mục tiêu: Đánh giá mức độ hài lòng và các yếu tố ảnh hưởng đến sự hài lòng của người bệnh đối với việc cấp phát thuốc ngoại trú. Đối tượng và phương pháp:Các người bệnh đến thăm khám và tiếp nhận dịch vụ cấp phát thuốc ngoại trú ở bệnh viện Thống Nhất. Ṅghiên cứu cắt ngang quan sát người bệnh đến thăm khám và tiếp nhận dịch vụ cấp phát thuốc ngoại trú tại khu $C 5$ và Phòng khám $A$ Bệnh viện Thống Nhất. Bộ câu hỏi nghiên cứu trích từ một nghiên cứu quốc tếđã đảm bảo giá trị và độ tin cậy,với thang điểm đánh giá Likert năm mức độ, từ "Rất không hài lòng" (1) đến "Rất hài lòng" (5). Nghiên cứu xử lý, phân tích và trình bày số liệu bằng SPSS. Kết quả: Với 300 người bệnh khảo sát, điểm trung bình hài lòng chung của người bệnh đối với dịch vụ dược ngoại trú tại Bệnh viện Thống Nhất là cao (với 3,90 điểm). Bên cạnh đó, tiều chí có mức độ hài lòng được đánh giá cào nhất là sự rõ ràng của nhãn thuốc hoặc nhãn dán (với 4,47 điểm) và ngược lại, tiêu chí có điểm trung bình thấp nhất là sự tiện nghi tại nơi nhận thuốc (với 3,20 điểm). Ngoài ra, sư hài lò̀ng tổng thể đối của người bệnhvới dịch vư dược ngoại trú tại Phòng khám A thấp hơn khi so sánh tại khu C5. Kết luận: Nhìn chung, đa số người bệnhcho rằng họ cảm thấy hài lòng hoặc rất hài lòng khi đến khám và sử dụng dịch vụ dược ngoại trú tại Bệnh viện Thống Nhất.

Tử khóa: Sự hài lò̀ng, cấp phát thuốc ngoại trú, bệnh viện Thống Nhất

${ }^{1}$ Bênh viện Thống Nhất

ª̣ai học Công nghệ TP. Hồ Chí Minh

${ }^{3}$ Đai hoc Y khoa Pham Ngoc Thạch

Chịu trách nhiệm chính: Võ Quang Trung

Email: trungvq@pnt.edu.vn

Ngày nhân bài: $27 / 8 / 2021$

Ngày phản biên khoa họ: 23/9/2021

Ngày duyệt bài: 18/10/2021

\section{SUMMARY}

\section{PATIENT SATISFACTION FOR OUTPATIENT} DRUG DISPENSING AT THONG NHAT HOSPITAL

Objectives:To evaluate the factors affecting patient satisfaction with outpatient drug dispensing services. Subjects and methods: A cross-sectional study on patients who come to visit and receive outpatient drug dispensing services at C5 and Clinic A of Thong Nhat Hospital. The questionnaire used in an international study has guaranteed validity and reliability, rated on a 5-point Likert scale, from "Very Unsatisfied" (1) to "Very Satisfied" (5). Analyzing and processing data using SPSS. Results:With 300 patients surveyed, the average score of overall patient satisfaction with outpatient pharmacy services at Thong Nhat Hospital was high (mean score $=3.90$ ). In which the criterion with the highest average satisfaction score is the clarity of the drug label or sticker (mean score=4.47) and the criterion with the lowest average score on satisfaction is the facilities at the drug collection site (mean score $=3.20$ ). The mean value of overall satisfaction with outpatient pharmacy services of patients at Clinic A was lower than that of patients at site C5. Conclusion: In general, the majority of patients participating in the survey said they feel satisfied or very satisfied with the criteria related to outpatient pharmacy services at Thong Nhat Hospital.

Keywords: Satisfaction, Outpatient drug dispensing, Thong Nhat Hospital.

\section{I. ĐẶT VẤN ĐỀ}

Trên toàn câu, các dịch vụ dược phẩm đang chuyển trọng tâm từ chăm sóc lấy sản phẩm làm trung tâm sang chăm sóc dược phẩm lấy người bệnh làm trung tâm[1]. Theo định nghĩa, chăm sóc dược có trách nhiệm cung cấp các giải pháp 
hiệu quả, đạt mục tiêu điều trị cụ thể để góp phần nâng cao chất lượng sống của người bệnh. [2]. Trong thập kỷ qua, sự hài lòng của người bênh đối với các dịch vu chăm sóc sức khỏe tai các cơ sở y tế đã trở thành mối quan tâm lớn trong nỗ lực cải thiện kết quả điều trị của người bệnh. Các nghiên cứu cho thấy khi những người bểnhcảm thấy hài lòng, họ có khả năng tuân thủ điêu trị cao hơnvàtiếp nhận các dịch vụ chăm sóc y tế tốt hơn[3].

Người bệnh ngày nay nhận thức tốt hơn, được giáo dục và được cung cấp thông tinnêncó nhiều mong đợi hơn về hệ thống y tế. Việc thiết lập và thực hiện đánh giámức độ hài lòng của người bệnh đối với các dịch vụ dược phẩm là cần thiết với mục tiêunhận biết những mong đợi này và các tiêu chí thực hiện chưahợp lý để có hành động khắc phục và cải thiện chất lượng dịch vụ. Vì vậy, cần tiển hành khảo sát đánh giámức độ hài lòng của người bệnh đối với dịch vụ cấp phát ngoại trú của Bệnh viện Thống Nhất.

\section{II. ĐỐl TƯƠNG VÀ PHƯƠNG PHÁP NGHIÊN CỨU}

2.1. Đối tượng nghiên cứu: Các người bệnhđến khám và có sử dụng dịch vụ cấp phát thuốc ngoại trú tại khu $C 5$ và Phòng khám $A$ Bênh viên Thống Nhất, thỏa mãn tiêu chí lựa chọn: có đủ nhận thức về hành vi, có khả năng đọc viết tiếng Việt, đã nhận được ít nhất một đởn thuốc từ khu C5 hoặc Phòng khám $A$ tại Bệnh viện Thống Nhất và sẵn sàng tham gia khảo sát.

2.2. Địa điểm nghiên cứu:Tại các kho cấp phát thuốc ngoại trú Bệnh viện Thống Nhất là khu $C 5$ và Phòng khám $A$.

2.3. Thời gian nghiên cứu:Tháng $03 / 2021$.

2.4. Phương pháp nghiên cứu:Nghiên cứu cắt ngang sử dụng phương pháp thống kê mô tả và phép phân tích định tính với bộ câu hỏi khảo sát được tríchmột bài nghiên quốc tế[4]. Các câu hỏi trong mỗi tiêu chí được phân tích tích cực bằng cách sử dụng thang điểm Likert với mức năm thang bậc, từ mức 1 - hoàn toàn không hài lòng đến mức 5- hoàn toàn hài lòng. Phần thứ nhất với 22 câu hỏi bao gồm thời gian chờ nhận thuốc (hai); thái độ của dược sĩ (năm); cung cấp thuốc (năm); địa điểm khoa dược (bốn); và sự giáo dục người bệnh về cách sử dụng thuốc (sáu). Một câu hỏi mở ghi nhận ý kiến của người trả lời về cách cải thiên dịch vu cấp phát thuốc ngoại trú. Phần thứ hai của bảng câu hỏi bao gồm các đặc điểm của người bệnh bao gồm lứa tuổi, giới tính, thu nhập hàng tháng, tình trạng hôn nhân, trình độ học vấn, tần suất sứ dụng thuốc.

Để đảm bảo tính hợp lệ trong bối cảnh Việt Nam, bảng câu hỏi đã được dịch từ nguyên bản tiếng Anh sang tiếng Việt. Tất cả lỗi hoặc hiểu lầm về ngôn ngữ đã được thảo luận và điều chỉnh để tạo ra phiên bản tiếng Việt chính thức.

Cuộc phỏng vấn được thực hiện trực tiếp. Nghiên cứu viên sẽ giải thích mục đích của nghiên cứu cho người bệnh và nếu đồng ý tham gia nghiên cứu, ho sẽ được phát một bảng câu hỏi để trả lời các câu hỏi khảo sát. Nếu người bệnh là người cao tuổi hoặc không cần trực tiếp điền vào biểu mẫu, nhân viên nghiên cứu sẽ phỏng vấn và ghi lại phản hồi của người bệnh vào phiếu trả lời.

2.5. Phương pháp phân tích: Nghiên cứu sử dụng phương pháp thống kê tần số và mô tảđể thể hiện các đặc điểm chung và sự phân bô của mức độ hài lòng người bệnh đối với từng câu hỏi. Điểm trung bình thấp cho thấy sự hài lòng của người bênh liên quan câu hỏi đó thấp và ngược lại, điểm trung bình cao chỉ ra rằng sự hài lòngđối với câu hỏi đó được đánh giá cao. Bên cạnh đó, kiểm định thống kê t-test độc lập và ANOVA một chiều được dùng để kiểm tra sự khác biệt về điểm trung bình của mức độ hài lòng người bệnhvới các đặc điểm chung khác nhau. Ngoài ra, nghiên cứu sử dụng hồi quy và phân tích tương quan Pearsonnhằm đánh giá mối tương quan giữa mức độ hài lòng của người bệnh đối với các tiêu chí của dịch vụ cấp phát thuốc ngoại trú và các kho cấp phát thuốc ngoại trú. Nghiên cứu đã được thông qua Hội đồng Đạo đức trong Nghiên cứu $Y$ sinh học của Bệnh viện Thống Nhất (Quyết định số 05/2021/BVTN-HĐYĐ về việc chấp thuận các vấn đề đạo đức NCYSH).

\section{KẾT QUẢ NGHIÊN CỨU}

3.1. Các đặc điểm chung của các người bệnh

Bảng 1. Đặc điểm các yêu tố chung của các người bệnh tham gia khảo sát $(n=300)$

\begin{tabular}{|c|c|c|c|}
\hline \multicolumn{2}{|c|}{ Biến khảo sát } & \multirow{2}{*}{$\begin{array}{c}\begin{array}{c}\text { Tân } \\
\text { số }\end{array} \\
24 \\
\end{array}$} & \multirow{2}{*}{$\begin{array}{l}\begin{array}{l}\text { Tỷ lê } \\
\text { (\%) }\end{array} \\
8,00\end{array}$} \\
\hline Tuối & $<30$ & & \\
\hline & $31-40$ & 23 & 7,67 \\
\hline & $41-60$ & 69 & 23,00 \\
\hline & Trên 60 & 184 & 61,33 \\
\hline Giới tính & Nam & 131 & 43,67 \\
\hline & Nữ & 169 & 56,33 \\
\hline $\begin{array}{l}\text { Tình trang } \\
\text { hôn nhân }\end{array}$ & Có gia đình & 274 & 91,33 \\
\hline & Độc thân & 26 & 8,67 \\
\hline $\begin{array}{l}\text { Tân suất sử } \\
\text { dung thuốc }\end{array}$ & Mỗi ngày & 220 & 73,33 \\
\hline & Chỉ khi cân & 80 & 26,67 \\
\hline $\begin{array}{c}\text { Trình độ học } \\
\text { vấn }\end{array}$ & Tiểu học/THCS & 36 & 12,00 \\
\hline
\end{tabular}




\begin{tabular}{|c|c|c|c|}
\hline & THPT & 95 & 31,67 \\
\hline & Đại học & 144 & 48,00 \\
\hline & Sau đại học & 10 & 3,33 \\
\hline & Từ chối trà lời & 15 & 5,00 \\
\hline $\begin{array}{c}\text { Thu nhập } \\
\text { hàng tháng }\end{array}$ & Dưới 5 triệu đồng & 10 & 3,33 \\
\hline & Từ 5-10triệu đồng & 63 & 21,00 \\
\hline & $\begin{array}{c}\text { Từ 10,1-15 triệu } \\
\text { đồng }\end{array}$ & 16 & 5,33 \\
\hline & $\begin{array}{c}\text { Từ 15,1-20 triệu } \\
\text { đồng }\end{array}$ & 4 & 1,33 \\
\hline & Trên 20 triệu đông & 4 & 1,33 \\
\hline & Từ chối trả lời & 203 & 67,67 \\
\hline
\end{tabular}

Nhận xét: Trong 300 người bênh khảo sát thì số người bệnh lớn hơn 60 tuổi có tỉ lệ lớn nhất $(61,33 \%)$; giới tính nữ chiếm đa số với với tỉ lệ $56,33 \% ; 91,33 \%$ đã có gia đình; đa số người bệnh phải dùng thuốc mỗi ngày $(73,33 \%)$; phần trăm người bệnh hoàn thành chương trình đại học chiếm tỉ lệ cao nhất (48,00\%).

2. Sự khác biệt về mức độ hài lòng khi so sánh các đặc điểm nhóm chung

Bảng 2. Sự khác biệt giữa mức độ hài lòng của người bệnhđối với các đặc điểm chung

\begin{tabular}{|c|c|c|c|}
\hline \multicolumn{2}{|c|}{ Biến khảo sát } & $\begin{array}{c}\text { Giá trị } \\
\text { trung bình }\end{array}$ & $\begin{array}{c}\text { P- } \\
\text { value }\end{array}$ \\
\hline Tuối & $<30$ & 3,96 & 0,77 \\
\hline & $31-40$ & 3,87 & \\
\hline & $41-60$ & 3,96 & \\
\hline Giới tính & Trên 60 & 3,96 & \\
\hline Nam & 3,92 & 0,29 \\
\hline $\begin{array}{c}\text { Tình tranng } \\
\text { hôn nhân }\end{array}$ & Nữ & 3,97 & \\
\hline & Có gia đình & 3,96 & 0,59 \\
\hline & Độc thân & 3,88 & \\
\hline
\end{tabular}

3. Sự hài lòng của người bệnh đối với dịch vụ cấp phát thuốc ngoại trú

Bảng 3. Giá trị trung bình đánh giá sụ hài lòng của người bệnh đối với các tiêu chí dịch vụ cấp phát thuốc ngoại trú

\begin{tabular}{|c|c|c|c|}
\hline \multicolumn{2}{|r|}{ Biến khảo sát } & \multirow{2}{*}{\begin{tabular}{|c|}
$\begin{array}{c}\text { Giá trị trung } \\
\text { bình }\end{array}$ \\
3,58 \\
\end{tabular}} & \multirow{2}{*}{$\begin{array}{c}\text { Đố lệch } \\
\text { chuẩn } \\
0,76 \\
0,\end{array}$} \\
\hline \multirow{2}{*}{$\begin{array}{l}\text { Thời gian chờ } \\
\text { nhận thuốc }\end{array}$} & Nhận thuốc trong khoảng thời gian hợp lý & & \\
\hline & $\begin{array}{l}\text { Thời gian chờ lînh thuốc thì có thế chấp nhận khi } \\
\text { xem xét đến chất lượng đơn thuốc }\end{array}$ & 3,56 & 0,73 \\
\hline \multirow{5}{*}{$\begin{array}{l}\text { Thái độ } \\
\text { dược sĩ }\end{array}$} & Dược sĩ giúp tôi lấy thuốc & 4,03 & 0,26 \\
\hline & Dược sĩ giúp tôi giải quyết mọi vấn đề khi nhận thuốc & 4,02 & 0,26 \\
\hline & Dươc sĩ trả lời những câu hỏi của tôi & 4,02 & 0,30 \\
\hline & Dược sĩ hiếu trường hợp bệnh của tôi & 4,02 & 0,29 \\
\hline & Dược sĩ đối xử với tôi với thái độ kính trọng & 4,01 & 0,36 \\
\hline \multirow{5}{*}{$\begin{array}{l}\text { Sự cung } \\
\text { cấp thuốc }\end{array}$} & Nhận đủ số lượng thuốc & 4,37 & 0,51 \\
\hline & Tất cả thuốc trong toa của tôi đều có trong khoa dược & 4,03 & 0,32 \\
\hline & Tên thuốc rõ ràng và dễ dàng đọc & 4,25 & 0,43 \\
\hline & Nhãn thuốc hoặc nhãn dán hướng dấn rõ ràng & 4,47 & 0,51 \\
\hline & Hình thức bên ngoại và chất lượng thuốc thì tốt & 4,46 & 0,53 \\
\hline
\end{tabular}

\begin{tabular}{|c|c|c|c|}
\hline $\begin{array}{l}\text { Tần suất dùng } \\
\text { thyốc }\end{array}$ & Mỗi ngày & 3,94 & 0,30 \\
\hline & Chỉ khi cần & 3,99 & \\
\hline $\begin{array}{c}\text { Trình độ học } \\
\text { vânn }\end{array}$ & $\begin{array}{c}\text { Tiểu } \\
\text { học/THCS }\end{array}$ & 4,00 & 0,60 \\
\hline & THPT & 3,98 & \\
\hline & Đại học & 3,92 & \\
\hline & Sau đại học & 3,90 & \\
\hline & $\begin{array}{c}\text { Từ chối trả } \\
\text { lời }\end{array}$ & 4,00 & \\
\hline $\begin{array}{l}\text { Thu nhâp } \\
\text { hàng tháng }\end{array}$ & $\begin{array}{l}\text { İt hơn } 5 \\
\text { triệu đồng }\end{array}$ & 4,00 & $\begin{array}{c}0,004 \\
*\end{array}$ \\
\hline & $\begin{array}{l}\text { 5-10 triệu } \\
\text { đồng }\end{array}$ & 3,97 & \\
\hline & $\begin{array}{c}10,1-15 \\
\text { triệu đồng }\end{array}$ & 4,00 & \\
\hline & $\begin{array}{c}15,1-20 \text { triệu } \\
\text { đồng }\end{array}$ & 4,00 & \\
\hline & $\begin{array}{c}\text { Hơn } 20 \text { triệu } \\
\text { đông }\end{array}$ & 3,50 & \\
\hline Kho nhận thuốc & Khu C5 & 4,01 & $0,01^{*}$ \\
\hline & Phòng khám $\mathrm{A}$ & $\begin{array}{r}3,89 \\
\tilde{N}\end{array}$ & \\
\hline
\end{tabular}

Nhận xét: Bảng 2 cho thấy rõ ràng rằng người bệnh nhận dịch vụ cấp phát ngoại trú tại Phòng khám $A$ có mức độ hài lòng chung thẩp hơn khi so sánh với người bệnh nhận dịch vụ cấp phát ngoại trú tại Phòng khám C5. Hơn nữa, mức thu nhập trung bình hàng tháng cho thấy sự khác biệt có ý nghĩa thống kê giữa các nhóm người bênh (P-value $<0,05)$. Ngược lại, các đặc điểm khác như giới tính, tình trạng hôn nhân và tần suất sử dụng thuốc cho thấy có không sự khác biệt mang ý nghĩa thống kê giữa các nhóm được phỏng vấn. 
VIETNAM MEDICAL JOURNAL N² - NOVEMBER - 2021

\begin{tabular}{|c|c|c|c|}
\hline \multirow{4}{*}{$\begin{array}{l}\text { Địa điểm } \\
\text { khoa dược }\end{array}$} & Nơi phát thuốc dề dàng tìm thấy & 4,11 & 0,37 \\
\hline & Nơi chờ nhận thuốc thì tiện nghi & 3,20 & 1,04 \\
\hline & Nơi chờ nhận thuốc thì sạch và chấp nhận được & 4,03 & 0,22 \\
\hline & Giờ làm việc khoa dược là phù hợp cho tôi & 4,02 & 0,27 \\
\hline \multirow{6}{*}{$\begin{array}{l}\text { Giáo dục người } \\
\text { bệnh về } \\
\text { sữ dụng thuốc }\end{array}$} & Dược sĩ giải thích lý do tôi sử dụng thuốc & 3,88 & 0,46 \\
\hline & Dược sĩ bảo tôi uống đúng liều thuốc & 3,87 & 0,49 \\
\hline & $\begin{array}{c}\text { Dược sĩ giải thích các loại thuốc của tôi có thể có tác } \\
\text { dung phu }\end{array}$ & 3,80 & 0,52 \\
\hline & Dược sĩ giải thích làm thế nào bảo quản thuốc của tôi & 3,81 & 0,50 \\
\hline & Tôi có đủ thời gian với dược sĩ & 3,84 & 0,48 \\
\hline & $\begin{array}{c}\text { Khoa dược đã cung cấp một khu vực riêng tư cho việc } \\
\text { hướng dẫn sử dụng thuốc }\end{array}$ & 3,86 & 0,49 \\
\hline Sự hài lòng tổng thể & Tôi hài lòng với dịch vụ dược & 3,95 & 0,38 \\
\hline
\end{tabular}

Nhân xét: Bảng 3 cho thãy rằng mức độ hài lòng của người bệnh dành cho nhãn thuốc hoặc nhãn dán hướng dẫn rõ ràng là cao nhất (giá trị trung bình $=4,47$ ), trong khi đó người bệnh nhận thấy họ cảm thấy hài lòng ít nhất về vấn đề liên quan tới sự tiện nghi tại nơi nhận thuốc (giá trị trung bình $=3,20$ ). Từ tiêu chí dược sĩ giúp tôi lấy thuốc đến tiêu chí giờ làm việc khoa dược là phù hợp cho tôi ngoại trừ tiêu chí nơi chờ nhân thuốc thì tiện nghi, điểm trung bình cho mối câu đều trên 4 trong khi đó các câu còn lại điểm trung bình cho mỗi câu đều không đạt đển mức 4. Tên thuốc rõ ràng và dễ dàng đọc có giá trị chênh lệch giữa điểm cao nhất và điểm thấp nhất không nhiêu, ở mức 4 cho điểm thấp nhất và 5 cho điểm cao nhất. Ngược lại, các câu còn lại trong Bảng 3 có sự chênh lệch lớn giữa mức điểm cao nhất và thấp nhất. Đối với sự hài lòng tổng thể, những người được hỏi có điểm thấp nhất là 2 trong khi điểm cao nhất là 5 , với giá trị trung bình $=3,95$.

4. Sự liên hệ giữa sự hài lòng về địa điểm nhận thuốc và kho nhận thuốc

Bảng 4. Mối tương quan giữamức độ hài lòng về địa điểm nhận thuốc và kho nhận thuốc

\begin{tabular}{|c|c|c|}
\hline \multirow[b]{2}{*}{ Tiêu chí } & \multicolumn{2}{|c|}{ Kho nhận thuốc } \\
\hline & \begin{tabular}{|l|} 
Hệ số \\
tương quan
\end{tabular} & P-value \\
\hline $\begin{array}{l}\text { Nơi phát thuốc dê dàng } \\
\text { tìm thấy }(\mathrm{C} 1)\end{array}$ & $0,33 * *$ & 0,00 \\
\hline $\begin{array}{c}\text { Nơi chờ nhâan thuốc thì tiện } \\
\text { nghi (C2) }\end{array}$ & $0,82 * *$ & 0,00 \\
\hline $\begin{array}{l}\text { Nơi chờ nhận thuốc thì } \\
\text { sạch và chấp nhận được } \\
\text { (C3) }\end{array}$ & $0,14 *$ & 0,02 \\
\hline $\begin{array}{l}\text { Giờ làm việc khoa dược là } \\
\text { phù hợp cho tôi (C4) }\end{array}$ & 0,10 & 0,09 \\
\hline
\end{tabular}

Nhận xét: Bảng 4 thể hiện rằng tiêu chí thời gian làm việc của khoa dược (C4) có giá trị Pvalue $=0,09$, chứng tỏ $C 4$ không có tương quan với kho nhận thuốc. Ngược lại, các giá trị P-value của nơi phát thuốc dể dàng tìm thấy (C1), nơi chờ nhận thuốc thì tiện nghi $(\mathrm{C} 2)$ và vệ sinh tại nơi chờ nhận thuốc (C3) đều <0,05 do đó các câu này có tương quan với kho nhận thuốc. Xem xét các giá trị hệ số tương quan trong Bảng 4 để so sánh mức độ tương quan giữa $\mathrm{C} 1, \mathrm{C} 2, \mathrm{C} 3$ và kho nhận thuốc giá trị hệ số tương quan giữa C2 và kho nhận thuốc là cao nhất (hệ số tương quan $=0,82$ ) thể hiện mối liên hệ tuyến tính chặt chẽ giữa $C 2$ và kho nhận thuốc là cao nhất.

Bảng 5. Kết quả phân tích hồi quy các yếu tố tương quan với các tiêu chí của kho nhận thuốc

\begin{tabular}{|c|c|c|}
\hline Tiêu chí & $\begin{array}{c}\text { Hề số chuấn } \\
\text { hóa Beta }\end{array}$ & $\begin{array}{c}\mathbf{P} \text { - } \\
\text { value }\end{array}$ \\
\hline $\begin{array}{c}\text { Nơi phát thuốc dế } \\
\text { dàng tìm thây (C1) }\end{array}$ & 0,12 & 0,002 \\
\hline $\begin{array}{c}\text { Nơi chờ nhận thuốc } \\
\text { thì tiện nghi (C2) }\end{array}$ & 0,84 & 0,00 \\
\hline $\begin{array}{c}\text { Nơi chờ nhần thuốc } \\
\text { thì sạch và chấp } \\
\text { nhận được (C3) }\end{array}$ & $-0,18$ & 0,00 \\
\hline \multicolumn{2}{|c|}{ Adjusted R Square: 0,69} \\
\hline
\end{tabular}

Nhận xét: Bảng 5 thể hiện giá trị của hệ số chuẩn hóa (Beta) và giá trị $P$-value cho mô hình hồi quy tuyến tính bội. Kho nhận thuốc chịu tác động bởi 3 yếu tố: nơi phát thuốc dễ dàng tìm thấy, nơi chờ nhận thuốc thì tiện nghi và nơi chờ nhận thuốc thì sạch sẽ và chấp nhận được. Các biến này tạo ra một dự báo có ý nghĩa thống kê đối với kho nhận thuốc (P-value $<0,05)$. Giá trị beta lớn nhất là 0,84 thuộc về nơi chờ nhận thuốc thì tiện nghi, tiếp theo là nơi chờ nhận thuốc thì sạch sẽ và chấp nhận được $(-0,18)$ và cuối cùng là nơi phát thuốc dễ dàng tìm thấy $(0,12)$.

\section{BÀN LUẬN}

Kết quả nghiên cứu cho thây có sự khác biệt có ý nghĩa thống kê giữa khu C5 và Phòng khám A Bệnh viện Thống Nhất về sự hài lòng giữa hai 
nhóm người bệnh sử dụng dịch vụ cấp phát thuốc. Cụ thể, điểm trung bình mức độ hài lòng về của các người bệnh tiếp nhận dịch vụ cấp phát thuốc ngoại trú tại khu C5 Bệnh viện Thống Nhất cao hơn so với Phòng khám A. Nguyên nhândẫn đến sự khác biệt này có thể một phần do các người bệnh tại Phòng khám $A$ đa phần là các cán bộ trong khi các người bệnh nhận thuốc tại khu C5 thuộc diện dưới mức lương. Bên cạnh đó, đa phần người bệnh ở Phòng khám $A$ là người bệnhlớn hơn 60 tuổi và có trình độ đại học. Khi so sánh các cuộc nghiên cứutrên thế giới, nghiên cứu của tác giả Abdrrahman Shemsu Surur và các cộng sự cho thây mức độ hài lòng giữa các nhóm người bệnh khác nhau về trình độ học vấn và nhóm tuổicó sự khác biệt có ý nghĩa thống kê [5]. Bên cạnh đó, nhận định về sự khác biệt về mức độ hài lìng giữa các nhóm tuổi có ý nghĩa thống kể cũng được bảo vệ bởi nghiên cứu của Pinto $A R$ và các cộng sự [6]. Nhìn chung, tuy việc so sánh mức độ hài lòng của người bệnh giữa các nhóm người bệnh khác nhau đã được thực hiện bởi rất nhiều các nghiên cứu ở nhiểu quốc gia khác nhau, tuy nhiên các nghiên cứu vâ̂n còn nhiều khuyết điểm dẫn đến kết quả khảo sát rất đa dạng.

Những kết quả về điểm trung bình mức độ hài lòng đối với dịch vụ cấp phát thuốc ngoại trú tại Bệnh viện Thống Nhất chỉ ra rằng các tiêu chí nhận đủ sổ lượng thuốc, nhãn thuốc hoặc nhãn dán hướng dẫn rõ ràng, hình thức bên ngoài và chất lượng thuốc thì tốt là ba biến sở hữu điểm trung bình về sự hài lòng người bệnh khá cao (trên 4,30 điểm). Các kết quả khảo sát được tìm ra ở phần này có một vài điểm giống với nghiên cứu được thực hiện bởi tác giả Khudair và các cộng sự[[4]. Cả hai bài nghiên cứu sử dụng cùng một bộ câu hỏi đều cho thấy mức độ hài lòng của người bệnh ở đa số các câu hỏi khảo sát đều có điểm trung bình trên 3.5 và điểm trung bình sự hài lòng của người bệnhvới cung cấp đủ số lượng thuốc, nhãn thuốc hoặc nhãn dán hướng dẫn rõ ràng, hình thức bên ngoài và chất lượng thuốc tốt đều thuộc những vị trí điểm cao.

Kết quả của nghiên cứu này cho thấy có mối tương quan giữa nơi tiếp nhận thuốc và sự hài lòng của người bệnh. Một nghiên cứu của Sahat Manampin Siahaan và các cộng sự cũng cho thây sự hài lòng về địa điểm cấp phát thuốc phần nào ảnh hưởng đến sự hài lòng của người bệnh đối với dịch vụ của nhà thuốc ngoại trú [7]. Nghiên cứu của tác giả Sa'adah cùng các cộng sự cũng ủng hộ cho nhận định này[8]. Hơn nữa, nghiên cứu của Khudair và cộng sự cho thấy rằng một nơi cấp phát thuốc tốt sẽ có xu hướng làm tăng sự hài lòng của người bệnh đối với dịch vụ cấp phát thuốc ngoại trú[4].

Nghiên cứu cũng ghi nhận một số hạn chế khi thực hiện khảo sát. Do ảnh hưởng của dịch Covid-19 diễn biến phức tạp nên rất nhiều người bệnhcó tâm lý lo lắng, ngại giao tiếp với người khác. Đây là nguyên nhân làm kết quả nghiên cứu có thể bị ảnh hưởng bởi vì người bệnh trả lời các câu khảo sát nhanh và không cẩn thận nhằm kết thúc nhanh cuộc khảo sát. Bên cạnh đó, các nhóm người bệnh theo đặc điểm chung khác nhauphân bố không đồng đều dẫn đến khó quan sát sự khác biệt về mức độ hài lòng giữa các nhóm người bệnh.

\section{KẾT LUẬN}

Đa số người bệnh đều cho biết họ cảm thấy hài lòng hoăc rất hài lòng với các tiêu chí liên quan đến dịch vụ dược ngoại trú tại Bệnh viện Thống Nhất được với phần trăm người bệnh cảm thây hài lòng hoặc rất hài lòng trên $64 \%$ ở hầu hết các tiêu chí. Kết quả này có thể là một gợi ý cho các nghiên cứu trong tương lai nhằm nâng cao chất lượng chăm sóc y tế cho người dân.

\section{TÀI LIỆU THAM KHẢO}

1. Berenguer, B., et al., Pharmaceutical care: past, present and future. Current pharmaceutical design, 2004. 10(31): p. 3931-3946.

2. Hepler, C.D. and L.M. Strand, Opportunities and responsibilities in pharmaceutical care. American journal of hospital pharmacy, 1990. 47(3): p. 533-543.

3. Asadi-Lari, M., M. Tamburini, and D. Gray, Patients' needs, satisfaction, and health related quality of life: towards a comprehensive model. Health and quality of life outcomes, 2004. 2(1): p. 1-15.

4. Khudair, I.F. and S.A. Raza, Measuring patients' satisfaction with pharmaceutical services at a public hospital in Qatar. International journal of health care quality assurance, 2013.

5. Surur, A.S., et al., Satisfaction of clients with the services of an outpatient pharmacy at a university hospital in northwestern Ethiopia: a cross-sectional study. BMC health services research, 2015. 15(1): p. 1-8.

6. Pinto, A.R., et al., Users satisfaction regarding the service provided in community pharmacies. Advances in Pharmacology and Pharmacy, 2014. 2: p. 18-29.

7. Siahaan, S.M., L. Hakim, and T. Hariyanti, THE EFFECT OF THE QUALITY OF PHARMACEUTICAL SERVICE ON OUTPATIENT SATISFACTION OF AMELIA HOSPITAL. Jurnal Aplikasi Manajemen, 2018. 16(1): p. 115-124.

8. Sa'adah, E., T. Hariyanto, and F. Rohman, Pengaruh mutu pelayanan farmasi terhadap kepuasan dan loyalitas pasien rawat jalan dengan cara bayar tunai. Jurnal Aplikasi Manajemen, 2015. 13(1): p. 65-76. 